Orbis Tertius, vol. XXIV, nº 30, e125, noviembre 2019-abril 2020. ISSN 1851-7811

Universidad Nacional de La Plata

Facultad de Humanidades y Ciencias de la Educación

Centro de Estudios de Teoría y Crítica Literaria

\title{
Formas de la memoria inofensiva. Una lectura de la literatura de hijos
}

Harmless memory's forms. A reading of children's literature

Rocio Fit

Universidad Nacional del Comahue, Argentina

rociofit@gmail.com

\section{Resumen:}

Las escrituras de hijos de militantes perseguidos y desaparecidos se inscriben en una etapa diferenciada de la literatura postdictatorial en Argentina. En este articulo, se propone la lectura de estas narrativas a partir de la perspectiva desde la que Tamara Kamenszain aborda las escrituras del presente; en particular, ideas como las del testimonio inofensivo, la intimidad éxtima, la voz de la infancia permanente o la búsqueda por volver a casa funcionan productivamente para trabajar las formas en las que se vinculan literatura, memoria y vida en la literatura de hijos e hijas. En este sentido, se señalan rasgos sobresalientes de una moral de la forma -en términos barthesianosque, entre otras cosas, implica una nueva politica de la memoria en relación a las generaciones anteriores.

Palabras Clave: Narrativa argentina, autoficción, hijos de desaparecidos, memoria, dictadura.

\section{Abstract:}

The writings of disappeared activists' children take part from a defined stage of post-dictatorial literature in Argentina. In this article, we propose to read these narratives from Tamara Kamenszain's perspectives about the present's writing. Ideas such as harmless testimony, intimidad éxtima, permanent childhood's voice or returning home-create productive networks that allow us to read the ways in which literature, memory and life are linked. In this sense, we underline some outstanding features related to a moral of the form -in Barthes' expression-that, among other things, imply a new memory's politics in relation to previous generations.

KEYWORDS: Argentine narrative, self-fiction, disappeared activists' children, memory.

Si la gran pregunta que atravesó a los escritores, desde los setenta, fue cómo narrar la historia del horror, el interrogante que correspondió a la crítica fue cómo leer esa relación de la literatura con la historia, con el terror, con lo indecible; cómo leer las variaciones de ese vínculo en la transformación de las condiciones sociales y políticas. Esta periodización de las narrativas de historia reciente sugiere la presencia de distintas morales de la forma, es decir, de modos diferentes de pensar la Literatura en relación al compromiso y al valor político que se asume en la escritura. Para el Barthes de El grado cero de la escritura (2011) la historia formal de la literatura puede leerse como una historia de las ideas, en las que la escritura se despliega como la forma de un compromiso, en la elección de un tono o de un ethos del escritor. Nos preguntamos, entonces, por la variación de las formas que fue asumiendo la literatura en relación a la más atroz dictadura argentina.

Desde los primeros ensayos publicados a principios de los ochenta (AA.VV., 1987) hasta los trabajos más recientes, la crítica coincide en reconocer formas representación oblicuas, fragmentarias, alegóricas o elípticas en aquellas ficciones escritas durante la dictadura -de las cuales El vuelo del tigre (Moyano, 1980), Respiración artificial (Piglia, 1980) y Nadie, nada, nunca (Saer, 1980) son algunas de las obras señeras-. Se ha afirmado que el vacío sobre el que otros discursos no podían pronunciarse sin riesgo de muerte se presenta en las obras de la década como una posibilidad privilegiada de denunciar e incluso de hacer justicia (Sarlo, 2007). Si toda experiencia literaria se caracteriza por buscar un lenguaje que nunca llega a completar su referencia como señala, entre otros, Blanchot (2002) -, la paradoja del decir sin decir es doble en el caso de la literatura escrita durante regímenes totalitarios. Para Lespada (2018), lo indecible remite, en el contexto dictatorial, a lo que está prohibido decir en tanto existe una censura explícita y, al mismo tiempo, refiere a la condición de inenarrables de los crímenes atroces que el lenguaje difícilmente puede nombrar. De este modo, los recursos 
elípticos actúan directamente sobre el silencio de los regímenes militares y producen la (no) representación de la ausencia de los miles de desaparecidos. En síntesis, el contexto dictatorial refuerza la emergencia de una moral de la forma del desplazamiento o de la alegoría que se diferenció -necesariamente- de la estética de una escritura política ${ }^{1}$ de los sesenta y setenta, que presentaba sin rodeos la urgencia de la lucha revolucionaria.

En el retorno a la democracia, el Juicio a las Juntas y la publicación del informe de la CONADEP, Nunca más (1985) abrieron la puerta a un sinfín de narrativas testimoniales que significaron un hito decisivo en la construcción de las memorias de la dictadura (Gramuglio, 2002; Vezzetti, 2002). La investigación que se llevó adelante desde las instituciones recientemente recuperadas permitió establecer un sentido general del accionar del terrorismo de Estado, en una dimensión jurídica y política a la vez que simbólica. En este marco, también en los textos literarios comenzó a aparecer en primer plano la voz de víctimas y de los testigos para describir de un modo directo las prácticas de secuestro, de extorsión, de tortura y de desaparición de sus compañeros y compañeras. El poemario de Juan Gelman La junta luz: oratorio a las Madres de Plaza de Mayo (1985) y la novela de Miguel Bonasso Recuerdo de la muerte (1984) son algunas de las obras ejemplares del período en el que preponderaron las formas testimoniales.

A partir de mediados de los noventa, es posible percibir un nuevo corte en la periodización de los discursos posdictatoriales, a partir de las voces de genocidas que rompen el secreto militar -en particular, El vuelo (Verbitsky, 1995) - y de las de los hijos de detenidos-desaparecidos, algunos de los cuales fundan -entre 1995 y 1996- la agrupación nacional HIJOS (Hijos e Hijas por la Justicia contra el Olvido y el Silencio). Miguel Dalmaroni (2004) explica que a partir de este momento comienzan a escribirse relatos que buscan el efecto contrario a los procedimientos del cifrado y de la alegoría. Se trata de narraciones que presentan de modo directo las acciones más atroces, hacen hablar a las voces de las víctimas y de los victimarios, pero también a las de los "argentinos ordinarios", a las del consenso colectivo. Novelas como Villa (Guzmán, 1995), Dos veces junio (Kohan, 2002) o Ni muerto has perdido tu nombre (Guzmán, 2002) buscan un tono cuasi neutro que no se permita embellecer el horror, y a la vez, se aleje de la moral prefijada, en una búsqueda por recuperar la tensión entre la palabra bella y la palabra justa.

Esta breve historia de la literatura sobre la dictadura avanza en paralelo a una historización de las prácticas políticas, institucionales y simbólicas que fueron enmarcando una memoria social relativamente dominante, en una zona de necesarias disputas con otras memorias minoritarias o subterráneas (Pollak, 2006) que encontraron, según las coyunturas, más o menos posibilidades de decibilidad. A partir del 2003 y hasta el 2015, durante el gobierno kirchnerista, el Estado asume, además, un papel activo en relación a las políticas de derechos humanos que legitima e institucionaliza las prácticas, las conmemoraciones y los rituales de la memoria. Aunque el plano ideal discursivo promueve la pluralidad de tantas visiones como memorias haya, en la práctica tiende a reducirse a un relato dominante que reclama "el deber de la memoria" (Jelin, 2017).

Durante esa primera década del siglo XXI, comenzó a delinearse lo que percibimos como una nueva moral de la forma en las literaturas de la memoria: la de los hijos e hijas de militantes desaparecidos o perseguidos que tensionan la construcción de una memoria monumental. Estas nuevas escrituras se diferencian de una primera etapa de la producción de HIJOS, caracterizada por el testimonio de quienes "están desesperados por la historia de sus padres", como afirma Sarlo (2007) acerca de los relatos compilados por Gelman y La Madrid en Ni el flaco perdón de dios (1997). La película de Albertina Carri, Los rubios (2003), marca el inicio de un nuevo modo de escribir que desplaza la historia de los padres para narrar el trauma propio. Estas escrituras no solo dialogan con los sentidos instituidos por HIJOS en los noventa sino que también significan "la apertura de las poéticas del sentido hacia un más allá de los tabúes en torno a los modos de narrar el horror" (Basile, 2016, p. 166). 


\section{FORMAS DE LA MEMORIA INOFENSIVA}

En su ensayo Una intimidad inofensiva. Los que escriben con lo que hay (2016), Tamara Kamenszain propone una línea para pensar ciertas escrituras del presente, en las que lee a escritores excéntricos que no buscan ni la profundidad ni el escándalo. Por el contrario, practican su escritura en una inmediatez que genera el efecto de la infancia permanente, de la inocencia, de la intimidad inofensiva. Entre ellos, Félix Bruzzone exhibe una poética más lover que hater cuando las consignas que sostienen la militancia por la búsqueda de sus padres desaparecidos se vacía del contenido combativo y conflictivo de los años setenta. Ese desvío pacifico pero nada pasivo, dice la crítica, también se sostiene en la actitud del post-flaneur que anda con la casa a cuestas: "En semejante casa, la intimidad de puertas abiertas deviene éxtima y transforma, al ritmo subjetivo del ritornello, cualquier certeza acerca de la realidad pasada" (Kamenszain, p. 113).

Entre otras lecturas acerca del giro autobiográfico, del giro subjetivo o giro intimista de las literaturas del presente (Arfuch, 2002; Sarlo, 2005; Catelli, 2007) Kamenszain capta algunos rasgos que parecen describir la emergencia de una estructura de sentimiento, en los términos de Williams (2009), que se caracterizan por los atributos de lo inofensivo, de lo espontáneo, de los afectos amorosos. Esta perspectiva se complejiza cuando pensamos en los hijos que escriben en el presente narrativas que abordan, al mismo tiempo, la memoria íntima y colectiva y que explotan, vía la clave autoficcional, la tensión entre los límites de la ficción y el testimonio. En este sentido, planteamos la emergencia de una moral de la forma de la memoria inofensiva en algunas de las novelas de la segunda generación de hijos y destacamos algunos procedimientos mediante los cuales estas narrativas del yo modelan otras formas de la memoria en el presente.

En términos generales, se trata de escrituras que ponen en juego la memoria para volver a habitarla con otros sentidos y, de este modo, inscriben una distancia de los lugares de la memoria monumental o museificada. El Museo, dice Agamben (2013), es el lugar por excelencia de lo Improfanable, de lo que está expuesto pero ya no es, de lo que no puede ser usado o experimentado. En el inicio de Los topos (2014 [2008]), la primera novela de Félix Bruzzone, el protagonista avanza sin metas ni preocupaciones, como quien participa de un juego indefinido -e inofensivo- en el que solo importa pasarla bien:

\footnotetext{
No nos proponíamos escapar de nada sino que era una especie de juego, no sé cuál pero alguno. Tomábamos bastante alcohol y a veces alguien traía marihuana y todo era más divertido. La pasábamos bien. Íbamos a lugar para bailar pero no bailábamos. Hablábamos con cualquiera, inventábamos historias o contábamos partes reales de nuestras vidas haciendo grandes exageraciones (2014, p. 14).
}

El fragmento propone una clave de lectura metaficcional y autoficcional, a través de la cual la exageración y la invención se presentan como un juego que rebasa la propia historia hasta re-escribirla desfigurada. El juego es uno de los mecanismos de la profanación por excelencia, pues libera y restituye un objeto -separado en la esfera de lo sagrado, de lo intocable- al plano de la experiencia. Falsear el propio testimonio, darle otro uso, inventar derroteros insólitos, jugar con él es la forma más inmediata de liberarlo de su carácter sagrado y legitimado.

El narrador de Los topos, hijo de desaparecidos, cuestiona la idea de que exista una única lucha por la memoria que sea verdadera. Termina asistiendo a HIJOS por insistencia de una novia: "Ella siempre se empecinaba en ponerse por encima de mí, superior, ella mi salvadora y yo el idiota, el ciego que negaba trescientas veces la única verdad" (2008, p. 21). El personaje no encuentra sentido en las consignas de la militancia ni en los rituales memorísticos, como el de hacer carteles o remeras con fotografías de desaparecidos, como si fuesen ídolos de rock. Con una irreverencia cercana a la de Bartleby, el narrador prefiere no hacerlo: la búsqueda de sus padres, que debe emprender, entra en una suspensión interminable. Este desplazamiento le posibilita desligarse del sentido moral del deber de búsqueda y verdad, sin negarlas ni afirmarlas. 
La dificultad de ponerse en acción para buscar a los padres desaparecidos -la búsqueda imposible de un fantasma- se desplaza hacia otra búsqueda: es a partir del secuestro y desaparición de Maira que el protagonista se pone en movimiento y hace lo impensado por encontrarla y salvar su amor. La trama se precipita en esa búsqueda que también fracasa. El personaje deviene vagabundo, deviene travesti y, finalmente, topo -se transforma en el otro a quien buscaba-. A la vez, Maira es posiblemente su hermano desaparecido en cautiverio, y el Alemán -asesino de travestis y, posiblemente, de Maira- también podría llegar a ser -después de una serie de deducciones- su propio padre. Esta red familiar incestuosa refleja -como espejo oblicuo, desviado- el pasado en el presente:

A veces, ya en casa, me preguntaba si seguir a Maira no era una forma de evitar las averiguaciones sobre mi hermano. ¿Qué era primero, salvar el amor o el pasado? El presente y el futuro. ¿ Y el pasado? También, presente y futuro; pero la intensidad del pasado en el presente -y ni hablar en el futuro- era pequeña en comparación a la intensidad en el amor. Ese era mi orden, entonces: primero amor. Y en todo caso: por qué no pensar sólo en dos términos, pasado y futuro, y olvidarse del presente, que casi siempre era malo. En ese caso, no había dudas: futuro, Maira, amor infinito, libertad, sociedad nueva, mundo nuevo (p. 48).

Resulta de este orden de prioridades una suerte de consigna lover: primero amor. Esta elección desplaza la mirada del personaje del pasado hacia el futuro, en donde es posible construir una nueva sociedad desde el amor. De este modo, se abren las posibilidades para realizar una búsqueda cuyo final se conoce y quizás por eso se extiende infinitamente. El deseo, así como la búsqueda y como la literatura, es una realidad irreductible: en el momento en que se concreta, desaparece. Bruzzone renueva -vía la autoficción- la potencia de una experiencia de búsqueda que está del lado de la autenticidad de los afectos.

En esta línea, puede leerse, también, el Diario de una princesa montonera, 110\% verdad (2012) de Mariana Eva Pérez. La novela se construye a partir de las entradas publicadas en su blog homónimo. El diario íntimo escrito a la manera de un blog es un epítome de la intimidad como espectáculo, de la extimidad inofensiva: lo más íntimo de sí queda exhibido en el afuera sin ninguna pretensión de escándalo. La narración rebasa, con su $10 \%$ de exceso autoficcional, los discursos de la verdad (el diario, el testimonio) en los que se inscribe. El yo se configura como un personaje que conjuga en su nombre la ironía como procedimiento narrativo que tensiona los sentidos del léxico militante. La Princesa Montonera se inventa una jerga -militonta, hijis, temita- que minimiza la solemnidad de un lenguaje legitimado para hablar sobre los crímenes en la dictadura: "Mandá TEMITA al 2020 y participá de un fabuloso sorteo. ¡El show del temita! El reality de todos y todas. Humor, compromiso y sensualidad de la mano de nuestra anfitriona, que no se priva de nada a la hora de luchar por la Memoria, la Verdat ${ }^{2}$ y la Justicia” (2012, p. 39). Se distancia -vía el humor y la ironía- de las formas combativas de la generación de sus padres pero también de la propia, en sus años de militancia en HIJOS durante los noventa: "La Princesa está en las antípodas del Fervor Montonero pregonado por su padre. Las demostraciones políticas enardecidas le dan un poquito de vergüenza ajena. Ella es todo recato y pensamiento crítico. Detesta El que no salta es militar. Cantar de bronca no le sale” (p. 70).

También en la novela de Pérez, como en la de Bruzzone, el lugar de los rituales de la memoria -los homenajes, las marchas, las colocaciones de baldosas, la confección de remeras- es puesto en juego. ${ }^{3} \mathrm{Si}$ la función del rito es, explica Agamben (2015), preservar la continuidad de lo vivido, fijar y estructurar el tiempo, el juego, por el contrario, socava las estructuras y las transforma en acontecimientos. Cuando los hijos refieren en sus narraciones autoficcionales una experiencia distanciada, jocosa por momentos, sobre estos rituales abren la posibilidad de habitarlos como acontecimientos que rompen la fusión del pasado en el presente y lo devuelven a la diacronía. En otras palabras, no buscan la sincronía de la memoria ritual que detiene la imagen del pasado ni tampoco la que lo olvida por la atracción de un puro presente.

El desafío consiste en dar otro uso posible a las formas fijadas, volver a significarlas, "con qué nuevas palabras, cómo extraerme de la prosa institucional” (p. 46), se pregunta la narradora: “¿Podrála joven Princesa Montonera torcer su destino de militonta y devenir escritora?” (p. 46). Cada vez que la indignación, la 
tristeza, la solemnidad van tomando la prosa, interrumpe la voz que ironiza la megalomanía de un relator de historias de superhéroes, un chiste o alguna acción prosaica.

PRINCESA MONTONERA: Deberían poner el nombre de mi vieja en la puerta, porque esta es su pieza. [...] Yo quiero que pongan una estrella con el nombre de mi mamá en esta puerta, como en un camarín de Hollywood.

(Jota no le festeja el chiste. La envuelve en un abrazo interminable. Pasa por detrás de ella la visita guiada, se oyen explicaciones sobre la Pecera. Ella suspira e intenta zafarse, él se las ingenia para seguir abrazándola y además acariciarle el corazón. El grupo vuelve a pasar rumbo a Capuchita. Ella propone seguir. Suben la escalera que va a Capuchita, ella anteúltima, Jota al final. Jota aprovecha y le toca el culo. Ella es feliz. En la escalera que va de Capucha a Capuchita) (p. 18).

Diario... reclama un derecho que, como indica Carlos Gamerro (2015), la literatura se permite ejercer libremente: el derecho de los hijis a no tener sentimientos elevados, a no asumir el papel que la sociedad espera de ellos. Pero también, y fundamentalmente, el derecho a los deseos de felicidad y de amor en el presente, en el futuro.

Por su parte, las novelas La casa de los conejos (2008), de Laura Alcoba, y Pequeños combatientes (2013), de Raquel Robles, exhiben otra forma de la memoria inofensiva: la que hace escuchar la voz desde la infancia. En la boca de estas niñas -que saben demasiado para su edad, que se asumen como "pequeñas combatientes" y que buscan estar a la altura de las circunstancias- el lenguaje de la militancia no es parte de un juego, o bien, se trata de juego muy serio en el que se arriesga la vida. Ellas saben de su importancia: pueden delatar a una familia entera sin siquiera hablar, como muestra la anécdota del bebé que señala el escondite de sus padres, narrada por Alcoba. La protagonista, de siete años, vive la infancia clandestina de muchos de los hijos de militantes, entrenados por sus padres: "A mí ya me explicaron todo. Yo he comprendido y voy a obedecer. No voy a decir nada. Ni aunque vengan también a mi casa y me hagan daño. Ni aunque me retuerzan el brazo o me quemen con la plancha. Ni aunque me claven clavitos en las rodillas. Yo, yo he comprendido hasta qué punto callar es importante" (2008, p. 18). Al tiempo que describe el detrás de escena de la lucha armada, el relato deja fluir las urgencias de lo cotidiano. La voz de la niña condensa entonces la tensión ineludible que el mundo adulto no percibe. Ante descuidos en apariencia inofensivos, como simular que saca fotos con una cámara sin rollo, consigue la violencia y la incomprensión de los mayores y con ellos, la sensación de vergüenza, humillación y culpa de ser chica en una guerra de grandes:

- ¡No jugués más a eso! ¿Me entendiste?

Yo bajo la cabeza y me pongo a llorar. Muy quedamente. Hubiera querido que él no viera mis lágrimas, pero ya no consigo contener un sollozo, estrangulado pero perfectamente perceptible. Cuanto más intento reprimir mis lágrimas, más intensamente se sacude mi cuerpo (p. 61).

Yo no consigo hablar. Miro al Ingeniero, espantada. Quisiera dejar de mirarlo así, pero no consigo siquiera volver la cabeza. Estoy como clavada por sus dos ojos. Quisiera que él se calme, pero comprendo que lo que he hecho es gravísimo. Decididamente, no estoy a la altura (p. 100).

Cuando entra en el terreno del juego, el espacio-tiempo en el que se permite la distracción o la desestabilización, la protagonista pone a todos en peligro. Los lugares de la niñez -los juegos, las amigas, la escuela- pronto le estarán negados.

Antes que el desamparo o el desconcierto, son la impotencia y la culpa por no haber combatido para salvar a sus padres, los sentimientos que dominan a la niña de Pequeños combatientes. También en una voz autobiográfica que viene de la infancia, la novela comienza con la narración del día en que "se los llevaron":

Mi abuela decía que había sido así porque mis padres habían querido protegernos. Eso siempre me pareció totalmente ridículo: si nosotros éramos combatientes, si estábamos preparados para un momento así, sabíamos qué hacer, cuándo escondernos, cuándo correr, cuándo llorar. Sabíamos que teníamos que ser fuertes, sabíamos las cosas que podían pasar. Despertarse a la mañana y ver a mi abuela desencajada, tratando de ordenar la casa con su cuerpo enorme y disfuncional, repitiendo entre ahogos "se los llevaron, se los llevaron", fue horrible. ¡Ellos habían luchado durante la noche y yo había estado durmiendo! ¡Qué ser humano puede tener el sueño tan pesado! (2013, p. 11). 
La narradora organiza, junto a su hermano menor, un "Ejército Infantil de la Resistencia” mientras simula ser una nena normal: oculta su verdadera identidad de combatiente a la espera de órdenes del Partido para entrar en acción. El exceso de saber y de responsabilidad por parte de los niños, preparados por sus padres para enfrentar las situaciones límite, se enfrenta, a su vez, en lo que hoy parecería un exceso de ignorancia y de inocencia: la de esperar que ellos regresen, la de confiar en que pueden hacer algo para que eso suceda. Sin embargo, advierte Badagnani (2013), es precisamente el retorno al imaginario en el que la victoria de la revolución era una posibilidad concreta al que vuelve el relato de Robles, desde la posibilidad de relatarse a sí misma como la otra que era, como la niña que sentía y sabía -junto a sus padres- ese mundo posible.

La mirada desde la infancia de estas narradoras permite dar voz, treinta años después, a la experiencia de una niñez acallada por el terror, y a la vez, distanciarse del mundo adulto para hacer lugar a la memoria afectiva y familiar. Quizás, como señala Imperatore (2013), este contrapunto generacional sea uno de los mayores aportes de textos como estos: revisitar una experiencia política desde la intimidad y recuperar su memoria emotiva. Si la voz de la infancia permite esa visión desde una perspectiva extrañada de la realidad pero a la vez libre de prejuicios, también exhibe una posición impotentemente inofensiva: la voz de niños que no pudieron elegir, que no pudieron batallar, que debían "estar a la altura" y lo estuvieron, aunque no haya alcanzado.

En las novelas El espiritu de mis padres sigue subiendo en la lluvia (2011) de Patricio Pron y Soy un bravo piloto de la nueva China (2011) de Ernesto Semán, el motivo de la tensión inter-generacional se presenta a partir del regreso a la casa natal de los protagonistas que pronto desemboca en una búsqueda por entender al padre. "Los hijos somos los detectives de los padres, no policías, ni jueces" (2001, p. 12), asume el narrador de Pron en las primeras páginas de la novela. El joven retorna de Alemania habiendo perdido casi por completo la memoria por el consumo de algunas drogas. La búsqueda por recuperar los recuerdos de su padre -y también los propios- no solo se configura como el tema de la novela sino que únicamente es posible mediante su escritura, que se concreta a través de una trama fragmentaria, por momentos errática, y especular. ${ }^{4}$ En la espera por el despertar del padre enfermo, el hijo lee detenidamente una carpeta con recortes periodísticos sobre el crimen reciente de un vecino, hermano de una compañera militante desaparecida. Es en esa revisión de la investigación del padre -que parece distraerse de la trama principal-cuando el protagonista comienza a recordar, a intercalar asaltos de la infancia, relatos de sueños, descripciones de fotografías viejas, interrogaciones. De este modo, la escritura de su novela se constituye en un ir y venir del pasado, a través del cual el personaje reconoce los motivos traumáticos que lo llevaron a olvidar los eventos de la infancia: "decidí recordar y hacerlo por mí, por mi padre y por lo que ambos habíamos salido a buscar y nos había reunido sin que lo quisiéramos" (p. 195). La memoria se constituye así como una decisión, como un trabajo de búsqueda que el personaje solo puede realizar mediante la tarea inofensiva de la literatura, que hace aparecer no una verdad, no un juicio ni una condena, sino los afectos y afecciones de una vida.

También el protagonista de Soy un bravo piloto... recurre a la ficción para hacer aparecer aquello imposible de recuperar: la voz del militar que ha matado a su padre, el momento de su asesinato, las palabras que se dirían -represor y desaparecido- pasados los años. La novela transcurre, alternadamente, en tres espaciotiempos: "la ciudad", que refiere el regreso del protagonista a Buenos Aires para cuidar de su madre y que lo traslada a los recuerdos de la infancia; "el campo", narrado desde la perspectiva de Capitán, el represor que captura, tortura y tira al vacío al padre, desde uno de los "vuelos de la muerte"; finalmente, "la Isla", un escenario onírico, sin límites precisos, abierto en la mente de Rubén Abdela. De este espacio, que está guiado por unos extraños guardianes, se dice que "su forma y tamaño y peso cambiaban con el tiempo [...] y que también podrían ser totalmente diferentes de acuerdo a cada uno, en cada momento, a cómo la viera cada uno" (2011, p. 83). En este escenario, Semán configura una idea de memoria como espacio indeterminado en el que puede elegirse qué recuperar, qué imaginar, qué vacíos rellenar, antes que la expresión verdadera y unívoca del pasado; también, ironiza sobre la memoria como mercado, cuando los guías de la Isla le proponen realizar un reconciliation tour para explotar el turismo de la zona. Quizás, entre los múltiples sentidos que esta novela tiende en relación a la memoria, uno de los más sobresalientes es, en efecto, la imposibilidad de valerse 
de discursos sobre el pasado que reclamen el derecho a la Verdad. "La verdad es cosa de fachos" (p. 142), le enseña la abuela a Rubén cuando era un niño. Al mismo tiempo, aparece otra definición de verdad en la boca de Capitán: "La verdad no es la victoria. La verdad es torturar" (p. 230), que sitúa al hecho que perpetúa la tortura fuera de toda relativización y justificación sobre los relatos del pasado reciente. En su paso por la Isla (por la memoria), Abdela puede -así como el narrador de Pron- expresar un reclamo generacional y también comprender el lugar del padre. Ahora bien, una vez que logra esta suerte de aprendizaje, tiene que abandonar la Isla y encontrar la voz propia; "quizás lo más difícil allá abajo es encontrar la voz propia, en medio de tanto ruido” (p. 273), le aconsejan, como sugiriendo que la historia recién comienza.

\section{LA HISTORIA SIN FIN}

Leer la narrativa en torno a la última dictadura militar en Argentina a partir de la noción de moral de la forma nos permite subrayar el modo en que la literatura tensiona los discursos sociales, políticos y culturales, al tiempo que reconfigura las líneas de la tradición en la que se sostiene. En particular, la producción de la segunda generación de hijos, repensada desde la idea de intimidad inofensiva de Tamara Kamenszain, posibilita el trabajo sobre la literatura del presente desde una doble perspectiva: la de las narrativas de la memoria y la de las escrituras del yo. La memoria de la experiencia del pasado se hace siempre desde la subjetividad en el presente y, por lo tanto, se encuentra en permanente construcción. Los hijos transforman la experiencia del pasado inscribiendo en sus relatos una diferencia que hace posible el avance de la historia. Nos remitimos, una vez más, a Agamben cuando explica que, para que exista la historia, es preciso que el mundo de la estabilidad -representado por los adultos y los muertos-se relacione de manera dinámica con los significantes de la inestabilidad - los niños, larvas o fantasmas-. En otras palabras, se necesita que los niños se transformen en adultos, y que los fantasmas se transformen en muertos: "La verdadera continuidad histórica no es la que cree que se puede desembarazar de los significantes de la discontinuidad [...] sino que los acepta y los asume, 'jugando' con ellos, para restituirlos al pasado y transmitirlos al futuro" (Agamben, 2015, p. 124). La literatura de los hijos, quizás sin proponérselo, remueve tanto la presencia fantasmática de la generación desaparecida como la representación detenida de sí mismos en su función de "hijos de", para comenzar a pensar en el futuro de la historia.

La emergencia de esta nueva moral de la forma de las literaturas de la memoria -en relación a las formas del desplazamiento, del testimonio, del tono neutro que se escriben en los ochenta y los noventa- se deja pensar, entonces, como un final, como un cierre, solo en tanto consideremos a la clausura como atributo estructural de la literatura. Recuperando la paradoja de Blanchot, es el constante cuestionamiento de sí lo que hace imposible su definición pero también su desaparición, pues la esencia de la literatura consiste en una permanente huida de sí misma. ${ }^{5}$ Como afirma Giordano (2017), recordar esta tensión innata de la institución literaria es un gesto crítico necesario para resistir a discursos que proyectan la literatura de las dos últimas décadas en un sentido lineal y apocalíptico.

Por otra parte, sabemos con Barthes que, por muy productiva que resulte, es preciso abandonar la idea de moral de forma por una lectura ética de la literatura. Por fuera de los juicios de valor, por fuera de definiciones y clausuras, Kamenszain se pregunta cómo funciona, cómo avanza, qué pueden estas escrituras. Es a partir de estos interrogantes que podemos leer la etapa más reciente de las escrituras post-dictadura, porque sobre estas mismas preguntas -éticas, no morales- los hijos y las hijas escriben el presente, la memoria y la vida: desde una experiencia del testimonio inofensivo, que busca no una verdad de la historia sino una autenticidad de la experiencia, que se despega del mandato de la palabra del padre para oír la propia, que prefiere el tiempo del juego antes que el ritual, que profana las formas consagradas para inventarse otras, ni mejores ni peores, aunque sí más livianas, más amorosas, más felices. 


\section{REFERENCIAS}

AA.VV. (1987). Ficción y politica. La narrativa argentina durante el proceso militar. Buenos Aires, Argentina: Alianza. Agamben, G. (2013). Profanaciones. Buenos Aires, Argentina: Adriana Hidalgo.

Agamben, G. (2014). Desnudez. Buenos Aires, Argentina: Adriana Hidalgo.

Agamben, G. (2015). Infancia e historia. Buenos Aires, Argentina: Adriana Hidalgo.

Alcoba, L. [2008] 2010. La casa de los conejos. Buenos Aires, Argentina: Edhasa.

Arfuch, L. (2002). El espacio biográfico. Dilemas de la subjetividad contemporánea. Buenos Aires, Argentina: Fondo de Cultura Económica.

Arfuch, L. (2013). Memoria y autobiografia. Exploraciones en los limites. Buenos Aires, Argentina: Fondo de Cultura Económica.

Arfuch, L. (2016). Los 40 años: la tenacidad del recuerdo y el sinfín de los relatos. Revista Afuera, (16).

Badagnani, A. (2013). La memoria de los pequeños combatientes: Raquel Robles y la narrativa de los hijos de desaparecidos. Oficios Terrestres, 1(29). Recuperado de https://perio.unlp.edu.ar/ojs/index.php/oficiosterrestr es/article/view/1963

Barthes, R. (2011). El grado cero de la escritura: seguido de Nuevos ensayos criticos. Buenos Aires: Siglo XXI Editores.

Basile, T. (2016). La orfandad suspendida: la narrativa de Félix Bruzzone. CELEHIS, (32), pp. 141-169. Recuperdo de http://www.scielo.org.ar/scielo.php?script=sci_arttext\&pid=S2313-94632016000200011\&lng=es\&tlng=es

Blanchot, M. (2002). El espacio literario. Madrid, España: Editora Nacional.

Bonasso, M. (1984). Recuerdo de la muerte. Buenos Aires, Argentina: Planeta.

Bruzzone, F. [2008] (2014). Los topos. Buenos Aires, Argentina: Literatura Random House.

Catelli, N. (2007). En la era de la intimidad. Seguido del espacio biográfico. Rosario, Argentina: Beatriz Viterbo.

Dalmaroni, M. (2004). La palabra justa. Literatura, critica y memoria en la argentina (1960-2002). Santiago de Chile, Chile: Melusina Editorial.

Deleuze, G., Agamben, G. y Pardo, J. (2005). Preferiria no hacerlo. Bartleby el escribente de Herman Melville, seguido de tres ensayos sobre Bartleby. Valencia, España: Pretextos.

Gamerro, C. (2015). Facundo o Martín Fierro. Los libros que inventaron la Argentina. Buenos Aires, Argentina: Sudamericana.

Gelman, J. (1985). La junta luz: oratorio a las madres de plaza de mayo. Buenos Aires, Argentina: Colección de poesía Todos bailan/ Libros de tierra firme.

Gelman, J. y La Madrid, M. (1997). Ni el flaco perdón de dios. Hijos de desaparecidos. Buenos Aires, Argentina: Planeta.

Giordano, A. (1995). Roland Barthes. Literatura y poder. Buenos Aires, Argentina: Beatriz Viterbo.

Giordano, A. (2017). ¿A dónde va la literatura? La contemporaneidad de una institución anacrónica. El taco en la brea, (5).

Gramuglio, M. T. (2002). Políticas del decir y formas de la ficción. Novelas de la dictadura militar. Punto de vista, 25(74).

Guzmán, L. (1995). Villa. Buenos Aires, Argentina: Alfaguara.

Guzmán, L. (2002). Ni muerto has perdido tu nombre. Buenos Aires, Argentina: Sudamericana.

Imperatore, A. (2013). Una autobiografía oblicua: la memoria clandestina en Los pasajeros del Anna C. y La casa de los conejos de Laura Alcoba. Les Ateliers du SAL, (3), pp. 34-48.

Jelin, E. (2017). La lucha por el pasado. Cómo construimos la memoria social. Buenos Aires, Argentina: Siglo XXI.

Kamenszain, T. (2016). Una intimidad inofensiva. Los que escriben con lo que hay. Buenos Aires, Argentina: Eterna Cadencia Editora.

Kohan, M. (2002). Dos veces Junio. Buenos Aires, Argentina: Sudamericana. 
Lespada, G. (2018). Literatura y genocidio. El terrorismo de Estado en la narrativa argentina. En Jorge Monteleone (dir.). Una literatura en aflicción. Historia critica de la literatura argentina. Vol. 12. Buenos Aires, Argentina: Emecé.

Moyano, D. (1981). El vuelo del tigre. Madrid, España: Editoral Legasa.

Pérez, M. E. (2012). Diario de una princesa montonera. 110\% verdad. Buenos Aires, Argentina: Capital Intelectual.

Piglia, R. (1980). Respiración artificial. Buenos Aires, Argentina: Pomaire.

Pollak, M. (2006). Memoria, silencio y olvido. La construcción social de identidades frente a las situaciones límite. La Plata, Argentina: Al Margen Editorial.

Pron, P. (2012). El espiritu de mis padres sigue subiendo en la lluvia. Buenos Aires, Argentina: Mondadori.

Robles, R. (2013). Pequeños combatientes. Buenos Aires, Argentina: Alfaguara.

Saer, J. J. [1980] (2000). Nadie, nada, nunca. Buenos Aires, Argentina: Seix Barral.

Sarlo, B. (2005). Tiempo pasado. Cultura de la memoria y giro subjetivo. Una discusión. Buenos Aires, Argentina: Siglo Veintiuno Editores.

Sarlo, B. (2007). Sujetos y tecnologías. La novela después de la historia. En Escritos sobre literatura argentina. Buenos Aires, Argentina: Siglo Veintiuno Editores.

Sarlo, B. (2012). Ficciones argentinas. 33 ensayos. Buenos Aires, Argentina: Mardulce.

Semán, A. (2011). Soy un bravo piloto de la nueva China. Buenos Aires, Argentina: Mondadori.

Verbitsky, H. (1995). El vuelo. Buenos Aires, Argentina: Planeta.

Vezzeti, H (2002). Pasado y presente. Guerra, dictadura y sociedad en la Argentina. Buenos Aires, Argentina: Siglo Veintiuno Editores.

Williams, R. (2009). Marxismo y literatura. Buenos Aires, Argentina: Las cuarenta.

\section{Notas}

1 Así como la dictadura no comienza con el golpe en 1976, probablemente sea acertado hacer referencia a una instancia previa, una etapa pre-dictadura en la que las banderas de la izquierda jugaron un rol central. Puede leerse una moral de la forma en la literatura comprometida o la literatura politica que cobra fuerza en la Latinoamérica de los sesenta y setenta y que en Argentina puede sintetizarse en Operación Masacre de Rodolfo Walsh, pero también en novelas como Los pasos perdidos, de Francisco "Paco" Urondo. Ahora bien, como señaló Gamerro (2015), si estas son las escrituras hegemónicamente políticas en las que el compromiso se vuelca en una estética realista, en una visión que se quiere verdadera sobre el deber del ciudadano revolucionario, contemporáneamente hay otra voz que escribe poniendo en tensión la política militante setentista, como es el caso de El beso de la mujer araña (1976) o Pubis Angelical (1979) de Manuel Puig.

2 Pérez se vale del arcaísmo "Verdat" como otro recurso para operar un distanciamiento de las consignas establecidas sobre valores que pueden vaciarse en base a su universalización. En el uso deliberado de las mayúsculas también es plausible leer una distancia irónica sobre lo que es considerado importante: "El bebé que nació en la Esma y que Tengo que Encontrar" (p. 25); “Militonteamos juntas en la primera época del Proyecto Re Importante” (p. 67).

3 Cabe aclarar que esa distancia crítica -entre el humor y la ironía- no aleja a la narradora de las prácticas de la memoria, de las que sigue participando. Por ejemplo: "Redes sociales por la Memoria, la Verdat y la Justicia [...]. Yo me pongo la foto de Jose en el facebook y la de Paty en el twitter y posteo pavadas. En twitter no prende, pero el muro de Facebook se me llena de siluetas, desaparecidos, pañuelos, nuncamases, todo el merchandising" (p. 71); o "Como fan de Rodolfo Walsh que soy, ya decidí cómo voy a festejar el Día de la Memoria. Recibí una invitación para una performance callejera que quiere subrayar la acción de la Carta Abierta a la Junta Militar. ¡Oh, sí una performance! Seguro que ahí no diremos los Presentes" (p. 71); o "La marcha a Plaza de Mayo. También voy, Llevo la cámara de fotos para hacer el chiste de la memorycool-hunter en el blog, pero después ahí no me dan ganas. La marcha me la seca siempre” (p. 73).

4 Como parte de esta trama especular, Pron agrega un giro metaficcional. La novela que el padre del protagonista hubiese querido escribir es la misma que está narrando: “¿Cómo debía haber sido la novela que mi padre había querido escribir? Breve, hecha de fragmentos, con huecos allí donde mi padre no pudiera o no quisiera recordar algo, hecha de simetrías historias duplicándose a sí mismas una y otra vez como si fueran la mancha de tinta de un papel plegado hasta el cansancio, 
un tema mínimo repetido varias veces como una sinfonía o un monólogo de un idiota- y más triste que el día del padre en un orfanato" (2012, p. 161).

5 En un artículo reciente, Giordano recupera, vía Blanchot, la definición de literatura del primer romanticismo alemán. Según uno de los postulados del círculo de Jena, "el ser de la literatura es un proceso infinito de interrogación y cuestionamiento de sí misma que en su devenir impugna las respuestas que no acogen su ausencia de especificidad, que deniegan la paradoja sobre la que se instituye como proyecto irrealizable" (Giordano, 2017, p. 135). Esta es la tensión irresoluble que recupera Blanchot (2002) cuando se responde que la esencia de la literatura es su desaparición, que la literatura solo es ella misma si todavía no lo es. 